\title{
EDITORIAL
}

\section{Mesenchymal stem cells for graft-versus-host disease: a double edged sword?}

\author{
Leukemia (2008) 22, 463-465; doi:10.1038/leu.2008.25
}

Convincing evidence shows that mesenchymal stem cells (MSCs) possess immunomodulatory properties, which may play a role in the maintenance of peripheral tolerance, the induction of transplantation tolerance and control of autoimmunity. Although there already data supporting their clinical efficacy in controlling some of the problems of hemopoietic stem cell (HSC) transplantation, concerns remain over the potential of systemic immune suppression and tumor progression. In this issue of Leukemia, Ning et al. ${ }^{1}$ report the results of their study on the use of MSC for the prevention of graft-versus-host disease (GVHD) in patients with hematological malignancies subjected to allogeneic HSC transplantation. This is the first randomized study addressing benefits and disadvantages of MSC infusions in the context of HSC allografting. A total of 30 patients were enrolled, most of them with acute myeloid leukemia, and randomized to receive HSC from a HLA-identical sibling donor with or without culture-expanded MSC from the same HSC donor, at a dose range of $0.3-15.3 \times 10^{5}$ MSC per $\mathrm{kg}$. They found that only 1 out of 10 patients in the group receiving MSC developed grade II acute GVHD as compared to 8 out of 15 patients in the non-MSC group. Strikingly, the relapse rate of MSC group was significantly higher than that of non-MSC group (60 versus $20 \%$ ), leading to the conclusion that MSC efficiently prevent GVHD but also negatively affect graft-versus-leukemia (GVL).

Even before testing their clinical efficacy in animal models, ${ }^{2,3}$ the immunosuppressive capacities of MSC were evaluated in the field of clinical allogeneic HSC transplantation to prevent GVHD. In an open-label multicenter clinical trial from Lazarus et al., ${ }^{4} 1.0-5.0 \times 10^{6} \mathrm{~kg}^{-1}$ culture-expanded MSC derived from the bone marrow of the original HSC donor were coinfused with HSC in 46 patients. In comparison with historical controls, no difference in prevention of graft rejection and incidence of GVHD was observed. It was not surprising, therefore that the number of relapsing patients was unchanged.

The first experience with the use of MSC for the prevention of GVHD was reported by Lee et al., ${ }^{5}$ who suggested that the injection of MSC enhanced engraftment, accelerated immune reconstitution and suppressed GVHD following T-cell-depleted HLA haplotype-mismatched HSC transplantation in a 20-yearold woman with high-risk acute myelogenous leukemia. The first documented observation of the clinical efficacy in GVHD was reported by the Karolinska Transplant Centre, which successfully treated a 9-year-old boy with steroid-resistant grade IV acute GVHD using haploidentical third-party MSC. ${ }^{6}$ More recently, the results of a phase I-II study in children undergoing haploidentical HSC transplantation were reported. The co-transplantation of MSC from the same HSC donor was associated with a significant reduction of graft failure rate as compared to historic controls. ${ }^{7}$ Although very encouraging, the long-term outcome of both anecdotal and full series is not yet available.

The clinical efficacy is believed to be the consequence of the MSC-mediated immunosuppression but the mechanisms have not yet been elucidated. Regardless of the different experimental approaches and the diverse immune functions analyzed, MSC prevent the proliferation of $\mathrm{T}$ cells in response to mitogenic or antigenic stimuli both in humans and mice (reviewed in Dazzi and Horwood ${ }^{8}$ ). MSC also inhibit $\mathrm{B}^{9}$ and natural killer ${ }^{10}$ cell proliferation as well as dendritic cell differentiation and function. ${ }^{11}$ Glennie et al. ${ }^{12}$ demonstrated that MSC-mediated immunosuppression is produced via an antiproliferative effect, which arrests target cells at early stages of cell cycle. This translates in a profound inhibition of cell proliferation despite partial conservation of effector function. The molecular mechanisms underlying these effects are not yet clarified but are likely to be mediated by direct cell-to-cell interactions and soluble factors. Transforming growth factor- $\beta$, indoleamine deoxydase, prostaglandin E2, nitric oxide and most recently insulin-like growth factor-binding proteins have been proposed as candidate molecules (reviewed in Nauta and Fibbe ${ }^{13}$ ).

The antiproliferative effect of MSC is not confined to immune cells but also affects cells of different tissue origin, including hematopoietic and non-hematopoietic tumor cell lines. Similar to what was observed on $\mathrm{T}$ cells, the effect is associated to an accumulation of tumor cells predominantly in G1 phase associated with the downregulation of cyclin D2. ${ }^{14}$ Furthermore, it appears that stemness is not a property required to exhibit immunosuppressive/antiproliferative activity, but is a fundamental characteristic of all stroma, as fibroblasts and terminally differentiated mesenchymal cells also inhibit the proliferation and prevent the apoptosis of activated T cells. ${ }^{15-17}$ Therefore, the highly acclaimed MSC-mediated immunosuppression may but be a novel version of the known role of fibroblasts in the modulation of inflammation. ${ }^{18}$

The property of regulating stem cell renewal and differentiation as well as the capacity of suppressing cell proliferation can all be ascribed to the central role of stroma in the regulation of tissue generation, maintenance and repair in a specialized anatomic location, the 'niche' ${ }^{19}$ Cell-cycle regulation by the niche is critical for the fate of HSC, as the quiescent state is indispensable for HSC self-renewal and life-span. Stromal cells balance quiescence and cell division in the stem cell niche, thus regulating long-term hematopoiesis. ${ }^{20}$ The interplay between the supporting effects of MSC in stem cell growth and differentiation and their immunosuppressive properties has been exploited by some successful clinical experiences in idiopathic aplastic anemia, indicating the functional contribution of transplanted MSC to hematopoietic regeneration. ${ }^{7,21}$

The study published in this issue of Leukemia by Ning et al. is significant in that it shows in a randomized clinical trial that MSC transplantation, although beneficial, comes at a high price, as the prevention of GVHD is associated with a higher incidence of leukemia relapse. For those active in the field of HSC transplantation, these data are like a deja $v u$, when in the eighties we learnt that prevention of GVHD was associated with loss of GVL. ${ }^{22}$ In fact, the donor T cells contained in the HSC preparation do not discriminate between the transplantation antigens, namely the minor histocompatibility antigens, ${ }^{23}$ expressed on leukemia and on normal tissues. ${ }^{24}$ Therefore, as the T cells affecting GVHD and GVL are the same, it is not 
a surprise that the study by Ning et al. in this issue of Leukemia similarly shows increased leukemia relapse rate in patients treated with MSC. Not only is the MSC antiproliferative effect non-specific, but also in this case targeting GVHD has unavoidably led to impairment of GVL.

However, there is still an aspect that does not entirely fit with the data, that is, the absence of differences in the number of infectious events in the group of patients treated with MSC. A non-selective immunosuppression would have equally affected patients' antiviral immunity. Therefore, it is possible that other mechanisms are involved in the clinical consequences of MSC transplantation. Cancer is organized in a manner similar to normal tissue, resourced by sub-population of stem cells dependent on a stromal cell 'niche'. Multiple mechanisms are potentially capable to impair tumor eradication in HSC transplantation. ${ }^{25}$ Not only the dynamic interaction between cancer and stromal cells can favor tumor progression, ${ }^{14,26,27}$ but recent evidence supports the capability of the hematopoietic microenvironment to be the sole causative mechanism of cancer development. ${ }^{28}$ Thus, the transplantation of MSC could tip the balance in favor of growth and progression of leukemic cells.

The critical issues that we have outlined require an answer. In particular, distinguishing whether the increased relapse rate in the patients infused with MSC is the result of immunosuppression or the consequence of the 'niche' function is of fundamental importance for the future of MSC-based therapies. The investigation of MSC homing to the tumor may help in clarifying the mechanisms responsible for the clinical outcome. In fact, although there is evidence that MSC can expedite tumor metastasis by mechanisms depending on continuing contact with stromal cells, ${ }^{26}$ other models are not consistent with this prerequisite as the analysis of the tumor tissues failed to show the presence of MSC. ${ }^{14}$ Accordingly, tumors also grow faster when MSC are injected systemically or subcutaneously at sites distant from the tumor, thus suggesting the primary role of soluble factors. $^{29}$

In conclusion, the efficacy of MSC in GVHD is now being confirmed in this randomized study, which unfortunately has also revealed the expected drawback of increased disease relapse. Identifying the mechanisms responsible for the clinical effect is the only possibility to improve the outcome and provide crucial information to design the new trials for the treatment of autoimmune diseases developed from preclinical studies. ${ }^{30}$ One simple answer could be to use third-party MHC-mismatched MSC which, being rejected, ${ }^{31,32}$ may still allow to preserve the beneficial control of GVHD without affecting GVL.

\section{Acknowledgements}

This work was funded by the Leukemia Research Fund. The authors have no conflicts of interest to declare.

F Vianello and F Dazzi Stem Cell Biology, Division of Investigative Sciences and Kennedy Institute, Imperial College, London, UK E-mail: f.dazzi@imperial.ac.uk

\section{References}

1 Ning $\mathrm{H}$, Yang $\mathrm{F}$, Jiang $\mathrm{M}$, Liangding $\mathrm{H}$, Feng $\mathrm{K}$, Zhang J et al. The correlation between cotransplantation of mesenchymal stem cells and higher recurrence rate in hematologic Malignancy patients: outcome of a pilot clinical study. Leukemia 2008; 22: 593-599.

2 Sudres M, Norol F, Trenado A, Gregoire S, Charlotte F, Levacher B et al. Bone marrow mesenchymal stem cells suppress lymphocyte proliferation in vitro but fail to prevent graft-versus-host disease in mice. J Immunol 2006; 176: 7761-7767.

3 Tisato V, Naresh K, Girdlestone J, Navarrete C, Dazzi F. Mesenchymal stem cells of cord blood origin are effective at preventing but not treating graft-versus-host disease. Leukemia 2007; 21: 1992-1999.

4 Lazarus HM, Koc ON, Devine SM, Curtin P, Maziarz RT, Holland $\mathrm{HK}$ et al. Cotransplantation of HLA-identical sibling culture-expanded mesenchymal stem cells and hematopoietic stem cells in hematologic malignancy patients. Biol Blood Marrow Transplant 2005; 11: 389-398.

5 Lee ST, Jang JH, Cheong JW, Kim JS, Maemg HY, Hahn JS et al. Treatment of high-risk acute myelogenous leukaemia by myeloablative chemoradiotherapy followed by co-infusion of $\mathrm{T}$ celldepleted haematopoietic stem cells and culture-expanded marrow mesenchymal stem cells from a related donor with one fully mismatched human leucocyte antigen haplotype. $\mathrm{Br} J$ Haematol 2002; 118: 1128-1131.

6 Le Blanc K, Rasmusson I, Sundberg B, Gotherstrom C, Hassan M, Uzunel $\mathrm{M}$ et al. Treatment of severe acute graft-versus-host disease with third party haploidentical mesenchymal stem cells. Lancet 2004; 363: 1439-1441.

7 Ball LM, Bernardo ME, Roelofs H, Lankester A, Cometa A, Egeler RM et al. Cotransplantation of ex vivo expanded mesenchymal stem cells accelerates lymphocyte recovery and may reduce the risk of graft failure in haploidentical hematopoietic stem-cell transplantation. Blood 2007; 110: 2764-2767.

8 Dazzi F, Horwood NJ. Potential of mesenchymal stem cell therapy. Curr Opin Oncol 2007; 19: 650-655.

9 Corcione A, Benvenuto F, Ferretti E, Giunti D, Cappiello V, Cazzanti $\mathrm{F}$ et al. Human mesenchymal stem cells modulate B cell functions. Blood 2006; 107: 367-372.

10 Spaggiari GM, Capobianco A, Becchetti S, Mingari MC, Moretta L. Mesenchymal stem cell-natural killer cell interactions: evidence that activated NK cells are capable of killing MSCs, whereas MSCs can inhibit IL-2-induced NK-cell proliferation. Blood 2006; 107: 1484-1490.

11 Ramasamy R, Fazekasova H, Lam EW, Soeiro I, Lombardi G, Dazzi F. Mesenchymal stem cells inhibit dendritic cell differentiation and function by preventing entry into the cell cycle. Transplantation 2007; 83: 71-76.

12 Glennie S, Soeiro I, Dyson PJ, Lam EW, Dazzi F. Bone marrow mesenchymal stem cells induce division arrest anergy of activated T cells. Blood 2005; 105: 2821-2827.

13 Nauta AJ, Fibbe WE. Immunomodulatory properties of mesenchymal stromal cells. Blood 2007; 110: 3499-3506.

14 Ramasamy R, Lam EW, Soeiro I, Tisato V, Bonnet D, Dazzi F. Mesenchymal stem cells inhibit proliferation and apoptosis of tumor cells: impact on in vivo tumor growth. Leukemia 2007; 21: 304-310.

15 Bocelli-Tyndall C, Barbero A, Candrian C, Ceredig R, Tyndall A, Martin I. Human articular chondrocytes suppress in vitro proliferation of anti-CD3 activated peripheral blood mononuclear cells. J Cell Physiol 2006; 209: 732-734.

16 Haniffa MA, Wang XN, Holtick U, Rae M, Isaacs JD, Dickinson AM et al. Adult human fibroblasts are potent immunoregulatory cells and functionally equivalent to mesenchymal stem cells. J Immunol 2007; 179: 1595-1604.

17 Jones S, Horwood N, Cope A, Dazzi F. The antiproliferative effect of mesenchymal stem cells is a fundamental property shared by all stromal cells. J Immunol 2007; 179: 2824-2831.

18 Pilling D, Akbar AN, Girdlestone J, Orteu CH, Borthwick NJ, Amft $\mathrm{N}$ et al. Interferon-beta mediates stromal cell rescue of T cells from apoptosis. Eur J Immunol 1999; 29: 1041-1050.

19 Calvi LM, Adams GB, Weibrecht KW, Weber JM, Olson DP, Knight MC et al. Osteoblastic cells regulate the haematopoietic stem cell niche. Nature 2003; 425: 841-846.

20 Arai F, Hirao A, Ohmura M, Sato H, Matsuoka S, Takubo K et al. Tie2/angiopoietin-1 signaling regulates hematopoietic stem cell quiescence in the bone marrow niche. Cell 2004; 118: 149-161.

21 Le Blanc K, Samuelsson H, Gustafsson B, Remberger M, Sundberg B, Arvidson J et al. Transplantation of mesenchymal stem cells to enhance engraftment of hematopoietic stem cells. Leukemia 2007; 21: $1733-1738$. 
22 Goldman JM, Gale RP, Horowitz MM, Biggs JC, Champlin RE, Gluckman $\mathrm{E}$ et al. Bone marrow transplantation for chronic myelogenous leukemia in chronic phase. Increased risk for relapse associated with T-cell depletion. Ann Intern Med 1988; 108: 806-814.

23 Simpson E, Scott D, James E, Lombardi G, Cwynarski K, Dazzi F et al. Minor $\mathrm{H}$ antigens: genes and peptides. Eur J Immunogenet 2001; 28: 505-513.

24 Dazzi F, Szydlo RM, Goldman JM. Donor lymphocyte infusions for relapse of chronic myeloid leukemia after allogeneic stem cell transplant: where we now stand. Exp Hematol 1999; 27: 1477-1486.

25 Scadden DT. The stem-cell niche as an entity of action. Nature 2006; 441: 1075-1079.

26 Karnoub AE, Dash AB, Vo AP, Sullivan A, Brooks MW, Bell GW et al. Mesenchymal stem cells within tumour stroma promote breast cancer metastasis. Nature 2007; 449: 557-563.

27 Patocs A, Zhang L, Xu Y, Weber F, Caldes T, Mutter GL et al. Breast-cancer stromal cells with TP53 mutations and nodal metastases. N Engl J Med 2007; 357: 2543-2551.
28 Walkley CR, Olsen GH, Dworkin S, Fabb SA, Swann J, McArthur $\mathrm{GA}$ et al. A microenvironment-induced myeloproliferative syndrome caused by retinoic acid receptor gamma deficiency. Cell 2007; 129: 1097-1110.

29 Djouad F, Plence P, Bony C, Tropel P, Apparailly F, Sany J et al. Immunosuppressive effect of mesenchymal stem cells favors tumor growth in allogeneic animals. Blood 2003; 102: 3837-3844.

30 Zappia E, Casazza S, Pedemonte E, Benvenuto F, Bonanni I, Gerdoni $\mathrm{E}$ et al. Mesenchymal stem cells ameliorate experimental autoimmune encephalomyelitis inducing $\mathrm{T}$ cell anergy. Blood 2005; 106: 1755-1761.

31 Eliopoulos N, Stagg J, Lejeune L, Pommey S, Galipeau J. Allogeneic marrow stromal cells are immune rejected by MHC class I- and class II-mismatched recipient mice. Blood 2005; 106: 4057-4065.

32 Nauta AJ, Westerhuis G, Kruisselbrink AB, Lurvink EG, Willemze R, Fibbe WE. Donor-derived mesenchymal stem cells are immunogenic in an allogeneic host and stimulate donor graft rejection in a nonmyeloablative setting. Blood 2006; 108: 2114-2120. 